\title{
Bazı Pamuk (Gossypium hirsutum L.) Genotiplerinin (Melezler ve Ebeveyler) Lif verimi ve Erkencilik Yönünden Elbistan Koşullarına Uyum Yetenekleri ve Korelasyon Katsayılarının Belirlenmesi
}

\author{
Ramazan Şadet GÜVERCiN ${ }^{1^{*}}$ \\ ${ }^{1}$ Kahramanmaraş Sütçü İmam Üniversitesi, Türkoğlu Meslek Yüksek Okulu, Türkoğlu/Kahramanmaraş \\ [ORCID: http://orcid.org/0000-0002-6195-5762] \\ *Sorumlu yazar: rguvercin@ksu.edu.tr
}

Öz

Pamuk ıslahında temel amaç, erkenciliği lif verimi ve kalite ile birleştiren çeşit geliştirmektir. Bu çalışma, 2011 ve 2012 yıllarında, Akdeniz, iç Anadolu ve Doğu Anadolu Bölgelerinin kesişme noktasında konumlanmış, kısa vejetasyon süresi ve ortalama 950-1150 m yüksekliğe sahip Elbistan koşullarında yürütülmüştür. Bitkisel materyal olarak, sekiz pamuk (Gossypium hirsutum L.) çeşidinin (analar: Stoneville 468, Adana 98 ve Furkan; babalar: Beli izvor 432, Primera, Berke, Nazilli 663 ve Fantom) yanı sıra, bu çeşitlerden geliştirilmiş on beş melez $F_{1}$ kombinasyonunun kullanıldığı çalışmada, Line $x$ Tester analiz yöntemiyle, lif verimi ve dokuz erkencilik özelliği yönünden, genotiplerin (ebevynler ve melezler) uyum yetenekleri ile özellikler arası ilişkiler irdelenmiştir.

Çalışma sonucunda, lif verimi ile erkencilik özellikleri arasındaki arasındaki korelasyonun önemli olduğu ve ekim-ilk çiçek açma süresi hariç, diğer özelliklerin dominant ve/veya epistatik gen ile yönetildiği saptanmıştır. $1 \times 4$ melez $F_{1}$ kombinasyonu (Stoneville $468 \times$ Beli izvor 432), lif verimi ve günlük verim indeksi yönünden önemli özel uyuşma yeteneğine ve en yüksek lif verimine $\left(113.3 \mathrm{~kg} \mathrm{da}^{-1}\right)$ sahip olurken, taraklanma süresi, ekim-ilk çiçek açma süresi, ekim-ilk koza açma süresi, ortalama olgunluk süresi ve günlük verim indeksi yönünden de önemli bulunmuştur. Ayrıca, Fantom çeşidi ortalama olgunluk süresi yönünden önemli genel uyuşma yeteneği ile en yüksek lif verimine $\left(102.83 \mathrm{~kg} \mathrm{da}^{-1}\right)$ sahip olurken, hem ilk koza açma süresi hem de günlük verim indeksi yönünden önemli bulunmuştur.

Anahtar Kelimeler: Elbistan, pamuk (Gossypium hirsutum L.), Lif verimi ve erkencilik, Çoklu dizi ve uyum yetenekleri,Korelasyon katsayıları

\section{Determination of Combining Ability and Correlation Coefficients of Some Cotton (Gossypium hirsutum L.) Genotypies (Hybrids and Parents) in Elbistan Condition for Fiber Yield and Earliness}

\begin{abstract}
The main aim of cotton breeding is to develop new varieties which they are can be combined fiber yield with fiber quality and earliness.This study was conducted in 2011 and 2012 years (May-December period) on Elbistan plain for determine the suitable cotton genotypes which they have higher fiber yield and earliness. Elbistan is located in the junction of Mediterranean, Central Anatolia and Eastern Anatolia Region and has a short vegetation period with high altitude (950-1150 m) from see level in Turkey. In this study, eight cotton varieties and their fifteen $F_{1}$ hybrid were used as a material that they are belonging to Gossypium hirsutum L. species. All $\mathrm{F}_{1}$ hybrids have been developed by Line $\mathrm{x}$ Tester mating design, and investiged best genotypies for fiber yield and nine earlines characters.

As a result of this study, it was determined that fiber yield showed significant interaction with all earliness characteristics and all earliness characters are governed by dominant or epistatic effects of genes except sowing-first flowering time. $1 \times 4 \mathrm{~F}_{1}$ offspring was determined as best hybrid with fiber yield, squaring period, first flowering time, first boll opening time, average of maturity period and daily
\end{abstract}


output index, has very important SCA values for fiber yield and daily output index. The other way, Fantom cultivar was determined suitable parent for fiber yield, first boll opening time, average of maturity period, daily output index, and has very important GCA value for average of maturity period.

Key Words: Elbistan, cotton (Gossypium hirsutum L.), Fiber yield and earliness, Line $\mathrm{x}$ tester and combining ability, Correlation coefficient

\section{Giriş}

Erkenci pamuk çeşitlerin önemi, geç ekim veya ikinci ürün koşullarında anlaşılırken, ıslahçılarının temel amacı, erkenciliği lif verimi ve lif kalitesiyle birleştiren çeşit geliştirmektir. Pamuk erkenciliği, genetik yapının yanı sıra çevre ve kültürel uygulamalara göre değişmektedir (Kassianenko ve ark., 2003). Bu nedenle, yetiştirildiği bölgenin hasat döneminden daha erken olgunlaşanlar, erkenci çeşit olarak tanımlanmıştır (Bölek ve ark., 2007).

Çiçeklenme süresi kısa ve gelişme dönemi içinde ikinci çiçeklenme dönemine sahip olmayanlar genetik erkenciliğe (Bölek ve ark., 2007), sulama, besleme, hastalık-zararlı etkisi ve sık ekim gibi kültürel uygulamalara bağlı erkenciliğe sahip olanlar ise göreceli erkenciliğe sahip genotipler olarak sınıflandırılırken (Mert ve Akışcan, 1995), bu erkenciliklerin birlikte yönetimi, kısıtlı iklim koşullarına sahip bölgelerde, pamuk tarımı olasılığııı güçlendirmektedir.

Pamuk erkenciliğinde soğuğa tolerantık, fide çıkış gücü, kısa taraklanma ve koza olgunluk süresi ile ilk meyve dalı boğum sayısının önemli olduğu (Low ve ark., 1969; Gipson ve Ray, 1970; Muramoto ve ark., 1971; Hesketh ve ark., 1975; lqbal ve ark., 2003; Bednarz ve Nichols, 2005) bildirilirken,
Başbağ (1999), ilk çiçek açma süresi, birinci el kütlü oranı, ortalama olgunluk süresi ve günlük verim indeksinin önemli olduğunu saptamıştır.

Üretiminden daha fazla lif tüketen Türkiye, Çin'in ardından en fazla pamuk ithal eden ikinci ülkedir (Anonim, 2013 a). Bu durum, Amerika Birleşik Devletleri ve Yunanistan gibi bazı ülkelere bağımlılık oluştururken, çözüm olarak; diğer ürünlerin ekim alanlarında azalma oluşturmayan ikinci ürün pamuk tarımı ile erkenci çeşitlerin kısıtlı iklim koşullarına sahip bölgelerde yetiştirilmesi gündeme gelmiştir.

Kahramanmaraş il merkezine $162 \mathrm{~km}$ uzaklıkta, Akdeniz, iç̧ Anadolu ve Doğu Anadolu Bölgelerinin birleşim noktasında bulunan Elbistan Ovası, kısıtlı iklim koşullarına sahip bir bölgedir (Anonim, 2013 b). Daha önce pamuk tarımı yapılmamıs olan Elbistan ovası, uygun topoğrafya, toprak ve sıcaklık koşullarına sahip olmakla birlikte, ovanın deniz seviyesine olan yüksekliğinin yanı sıra (950-1150 m), ovadaki ilkbahar geç ve sonbahar erken donları ile gece-gündüz sıcaklık farkı, vejetasyon süresini kısaltan temel faktörlerlerdir.

Elbistan Ovası'na uygun pamuk çeşit ve/veya $F_{1}$ melez kombinasyonlarını belirlemek amacıyla, 2011 ve 2012 yıllarında yürütülen bu çalışmada, farklı özelliklere sahip sekiz pamuk çeşidinin 
yanı sıra bu çeşitlere ait on beş $F_{1}$ melez kombinasyonu kullanılılırken, genotiplerin lif verimi ve erkencilik özelliklerine ait genel ve özel uyum yetenekleri (GUY ve ÖUY) ile özellikler arası ilişkiler ve ebeveynlerin katkı oranları belirlenmiştir.

\section{Materyal ve Metot}

\section{Araştırma Yeri ve Özellikleri}

$\mathrm{Bu}$ araştırma, 2011 yılında, Kahramanmaraş'ta yapılan melezlemeleri takiben 2012 yılında, alüviyal, orta derece alkali ve kireç bakımından zengin topraklara sahip (Anonim, 2009 a), Elbistan koşullarında (N: $38^{\circ} 16^{\prime} 68^{\prime \prime}$; E: $37^{\circ} 05^{\prime} 24^{\prime \prime}$ ) yürütülmüştür. İlçede, düşük yağış ve nisbi nemin yanı sıra en sıcak günler Temmuz ve Ağustos aylarında görülürken, sıcaklık ortalamasının en yüksek olduğu dönem Ağustos ayıdır. Ovada yaz aylarına ait ortalama sıcaklıklar $25{ }^{\circ} \mathrm{C}$ ile $32.1{ }^{\circ} \mathrm{C}$ arasında değişmekle birlikte, ortalama sıcaklığın $25{ }^{\circ} \mathrm{C}$ ve üzeri olduğu yaklaşık 130 gün, Mayıs ve Kasım ayları arasında bulunmaktadır (Anonim, 2009 b).

\section{Bitkisel Materyal ve Kültürel Uygulamalar}

Ana ebeveynlerin verim, çırçır randımanı, yaprak tüylülüğü, yaprak şekli ve lif kalitesi, baba ebeveynlerin ise erkencilik yönünden tercih edildiği çalışmada, Gossypium hirsutum L. türüne ait sekiz pamuk çeşidi (analar: Stoneville
468, Adana 98 ve Furkan; babalar: Beli izvor 432, Primera, Berke, Nazilli 663 ve Fantom) ile bu çeşitlerin Line $\mathrm{x}$ Tester analiz yöntemine uygun melezlenmesiyle geliştirilmiş on beş $F_{1}$ melez kombinasyonu kullanılmıştır. Genotipler, 13 mayıs 2012 tarihinde, her parseli 16.8 $\mathrm{m}^{2}$ (6 m uzunluğunda, 2 sıra) olarak hazırlanan alana sıra arası $0.7 \mathrm{~m}$, sıra üzeri ise $0.30 \mathrm{~m}$ olacak şekilde, tesadüf blokları deneme deseninde, dört tekerrürlü ekilmiştir. Parsellere ekim ile birlikte $6 \mathrm{~kg} \mathrm{da}^{-1}$ saf azot $(N)$ ve fosfor $\left(\mathrm{P}_{2} \mathrm{O}_{5}\right)$ 20-20-0 kompoze, taraklanma döneminde ise $9 \mathrm{~kg} \mathrm{da}^{-1}$ saf azot $(N)$ üre formunda verilmiştir. Dört kez sulama yapılmıs ve hasatlar el ile 4 ekim 2012, 5 kasım 2012 ve 28 kasım 2012 tarihlerinde 3 kez yapılmıştır.

\section{Verilerin Değerlendirilmesi}

Hasatları takiben, özelliklere ait verilerle JMP 5.0.1 (SAS, 2002) programında varyans analizi yapılmış ve önemli genotiplere ait kareler ortalamaları, Line $\mathrm{x}$ Tester analiz yöntemine (Singh ve Chaudhry, 1985) uygun olarak melezler, ebeveynler ve melezler $\mathrm{x}$ ebeveynler bileşenlerine, melezler de analar, babalar ve analar $x$ babalar alt bileşenlerine ayrıştırılarak test edilmiştir. Sonuçlar F testi, ortalamalar arası farklılıklar ise LSD (Least significant differences) testiyle irdelenmiştir. Ebeveynlere ve melezlere ait uyuşma yetenekleri ise,

Analar GUY (GCA) (gi) $=(X i . . . /$ tr $)-(X . . /$ letr $)$

Babalar GUY (GCA) $(g j)=(X j \ldots /$ ler $)-(X . . /$ letr $)$

Analar x Babalar ÖUY (SCA) (Sij) $=(X i j . / r)-(X i . . / t r)-(X . j . / \ell r)+(X . . /$ etr $)$ 
formülleriyle saptanmıştır.

Eşitliklerde; $\quad X_{i j}=$ Melezlerin tekrarlamalar üzerinden toplam değeri, $\mathrm{X}_{\mathrm{i} . .}=$ analar toplamı, $\mathrm{X} . \mathrm{j}$ = babalar toplamı, $X . .=$ genel toplam, $r=$ tekrarlama sayısı, $\ell=$ ana sayısı, $t=$ baba sayısıdır.

Diğer yönden, tohum ekimini takiben, her parsele ait 10 bitkide, tarakların yaklaşık $1 \mathrm{~mm}$ olduğu ana kadar geçen gün sayısı; ekim-taraklanma süresi (gün), ilk tarağın oluşumundan ilk çiçeğin görülmesine kadar geçen süre; taraklanma süresi (gün), ilk çiçek açma tarihine kadar geçen süre; ekimçiçeklenme süresi (gün), ilk çiçek ile ilk koza açımı arasında geçen süre; çiçeklenme süresi (periyodu), ilk kozanın açma tarihine kadar geçen süre; ekim-ilk koza açma süresi (gün) ve ilk çiçeklerin görüldüğü tarih ile hasat edilebilir son kozanın açtığı gün aralığı; koza olgunlaşma süresi (gün) olarak belirlenirken, aynı bitkilerin kotiledon yapraklarından ilk meyve dalına kadar olan boğum sayısı; ilk meyve dalı boğum sayısı (adet) olarak saptanmıştır. Ayrıca, ortalama olgunluk süresi (OOS) ve günlük verim indeksi aşağıda verilen eşitlikler yardımıyla hesaplanmıştır. Günlük verim indeksi, bir dekarlık alandan, bir ortalama olgunluk gününde üretilen kütlü pamuk miktarını (kg) ifade etmektedir (Bilbro ve Quisenberry, 1975).

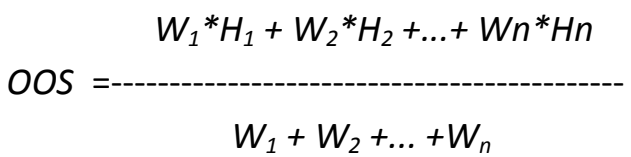

Eşitlikte;

$W_{1}, W_{2}, \ldots W n=$ Sirası ile 1. ve $2 . \mathrm{El}$ hasatta elde edilen kütlü pamuk miktarı (kg),

$\mathrm{H}_{1}, \mathrm{H}_{2}, \ldots \mathrm{Hn}=$ Sırası ile 1. ve 2. Hasada kadar geçen gün sayısını tanımlamaktadır.

$1,2 \ldots n=$ Periyodik hasat sayısı (Christidis ve Harrison, 1955).

\section{Kütlü verimi $\left(\mathrm{kg} \mathrm{da}^{-1}\right)$ \\ Günlük verim indeksi (\%) = \\ Ortalama olgunluk süresi (gün)}

Çalışmada, incelenen özelliklere ait Line $\mathrm{x}$ Tester analizleri ile ortalama olgunluk süresi ve günlük verim indeksi Microsoft excel paket programıyla saptanmıştır.

\section{Araştırırma Bulguları ve Tartışma}

varyasyona, analar arası (\% 40.77) ve babalar arası (\% 33.77) farklar ile analar $x$ babalar ilişkisi (\% 25.46) katkı verirken

\section{Lif Verimi}

Genotiplerin lif verimi, melezlerde; $59.1 \mathrm{~kg} \mathrm{da}^{-1}(3 \times 7)$ ile $113.3 \mathrm{~kg} \mathrm{da}^{-1}(1 \times 4)$ arasında değişerek ortalama $74.1 \mathrm{~kg} \mathrm{da}^{-1}$, ebeveynlerde ise; $50.0 \mathrm{~kg} \mathrm{da}^{-1}$ (Furkan) ile $102.8 \mathrm{~kg} \mathrm{da}{ }^{-1}$ (Fantom) arasında değişerek ortalama $72.6 \mathrm{~kg} \mathrm{da}^{-1}$ olarak gerçekleşmiştir (Çizelge 2). Bu (Çizelge 1 ve 4), ebeveynlerin GUY -10.60 (Furkan) ile 14.06 (Beli İzvor 432), melezlerin ÖUY ise -11.05 (2x4) ile 15.96 
(1x4) arasında değişmiştir. Genotiplerden Stoneville 468 ve Beli İzvor 432 ebeveynleri ile bu çeşitlerin melezi olan 1x4 $F_{1}$ kombinasyonu (Stoneville $468 \mathrm{x}$ Beli İzvor 432), sahip oldukları GUY (9.13 ve 14.06) ve ÖUY (15.96) ile dikkat çekerken, eklemeli olmayan gen etkisiyle $\left(\sigma_{\text {GUY }}^{2} / \sigma^{2}\right.$ öUY $\left.<1\right)$ yönetilen özelliğe ait bulguların, Shakeel ve ark., (2012) ile uyum gösterdiği belirlenmiştir (Çizelge 3 ). Bu durum, 1x4 kombinasyonunda melez (hibrit) gücüne işaret ederken, lif veriminin koza olgunlaşma süresi ve günlük verim indeksi haricindeki diğer erkencilik özellikleriyle negatif ve önemli korelasyona sahip olduğu saptanmıştır (Çizelge 5).

\section{Ekim-Taraklanma Süresi}

Önemli bir erkencilik belirteci olan ekim-taraklanma süresi, melezlerde; 51.0 gün (2x6) ile 57.0 gün $(3 \times 6)$ arasında değişerek ortalama 53.3 gün, ebeveynlerinde ise 53.8 gün (Fantom) ile 61.0 gün (Furkan) arasında değişerek ortalama 56.7 gün olmuştur. Bu farklılığa analar arası ve babalar arası varyasyonlar ile analar $\mathrm{x}$ babalar interaksiyonu katkı verirken, melezlerin ebeveynlerden daha erkenci olduğu belirlenmiştir (Çizelge 1 ve 2). Çalışmada, melezlerin ÖUY önemsiz, Furkan, Primera ve Berke ebeveynlerinin GUY ise önemli bulunurken (Çizelge 3), özelliğin eklemeli olmayan gen etkisiyle yönetildiği ve ekim-ilk çiçek açma süresinin yanı sıra koza olgunlaşma süresiyle pozitif, çiçeklenme süresi ve günlük verim indeksiyle de negatif korelasyon gösterdiği belirlenmiştir (Çizelge 5).

\section{Taraklanma Periyodu}

Analar arası farklılıklar, özellik yönünden, ebeveynler arası ve genotipler arası varyasyona \% 36.28, analar $\mathrm{x}$ babalar (LxT) ilişkisi ise melezler arası varyasyona \% 58.8 oranında destek vermiştir. Çalışmada, melezler ortalaması ile ebeveynler ortalaması arasında fark bulunmamakla birlikte, melezlerin taraklanma periyodu 18.8 gün $(1 \times 4)$ ile 24.3 gün $(2 \times 4)$ arasında değişerek ortalama 22.3 gün, ebeveynlerin taraklanma süresi ise 20.3 gün (Beli İzvor 432) ile 23.3 gün (Adana 98 ve Berke) arasında değişerek ortalama 22.6 gün olmuştur. Eklemeli olmayan gen etkisiyle $\left(\sigma^{2}{ }_{\text {GUY }} / \sigma^{2}\right.$ öUY $\left.<1\right)$ yönetilen taraklanma periyodu, koza olgunlaşma süresi ve günlük verim indeksi ile negatif, ekim-ilk çiçek açma, çiçeklenme periyodu, ekimilk koza açma ve ortalama olgunluk süreleri ile pozitif korelasyon gösterirken (Çizelge 3 ve 5), $2 \times 4 F_{1}$ melezine (Adana $98 \times$ Beli İzvor 432) ait ÖUY ile Adana 98 ebeveynine ait GUY önemli bulunmuştur. 
Çizelge 1. Elbistan koşullarında, incelenen özelliklere ilişkin Line x Tester analizleri

Table 1. Line $x$ Tester analysis for investigated properties in Elbistan conditions

\begin{tabular}{|c|c|c|c|c|c|c|c|c|c|c|c|c|c|c|c|c|c|c|c|c|c|}
\hline $\begin{array}{l}\text { Varyasyon kaynakları } \\
\text { Sourches }\end{array}$ & SD & $\begin{array}{c}\text { LV } \\
\mathrm{kg} \mathrm{da}{ }^{-1}\end{array}$ & & $\begin{array}{l}\text { Ets } \\
\text { gün } \\
\text { day }\end{array}$ & & $\begin{array}{c}\text { Tp } \\
\text { gün } \\
\text { day }\end{array}$ & & $\begin{array}{c}\text { Eiças } \\
\text { gün } \\
\text { day }\end{array}$ & & $\begin{array}{l}\text { Çp } \\
\text { gün } \\
\text { day }\end{array}$ & & $\begin{array}{c}\text { Eikas } \\
\text { gün } \\
\text { day }\end{array}$ & & $\begin{array}{l}\text { Kp } \\
\text { gün } \\
\text { day }\end{array}$ & & $\begin{array}{l}\text { Oos } \\
\text { gün } \\
\text { day }\end{array}$ & & Gv & & $\begin{array}{l}\text { İmdns } \\
\text { Adet } \\
\text { numbe }\end{array}$ & \\
\hline $\begin{array}{l}\text { Tekerrürler } \\
\text { Replications }\end{array}$ & 3 & 30.65 & & 31.05 & $* *$ & 1.32 & & 21.42 & $* *$ & 63.14 & $* *$ & 102.42 & $* *$ & 63.14 & $* *$ & 0.46 & & 0.02 & & 4.55 & $* *$ \\
\hline $\begin{array}{l}\text { Genotipler } \\
\text { Genotypies (G) }\end{array}$ & 22 & 987.62 & $* *$ & 26.36 & $* *$ & 5.95 & $* *$ & 32.33 & $* *$ & 194.59 & $* *$ & 191.11 & $* *$ & 194.59 & $* *$ & 25.32 & $* *$ & 0.21 & $* *$ & 1.08 & $* *$ \\
\hline $\begin{array}{l}\text { Ebeveynler } \\
\text { Parents (P) }\end{array}$ & 7 & 1710.73 & $* *$ & 21.78 & $* *$ & 4.13 & $* *$ & 32.75 & $* *$ & 62.21 & $* *$ & 54.85 & $* *$ & 368.50 & $* *$ & 0.26 & & 0.33 & $* *$ & 2.07 & $* *$ \\
\hline $\begin{array}{l}\text { Melezler } \\
\text { Hybrids (H) }\end{array}$ & 14 & 693.10 & $* *$ & 13.41 & $* *$ & 7.17 & $* *$ & 14.36 & $* *$ & 271.94 & $* *$ & 268.64 & $* *$ & 31.37 & $* *$ & 39.03 & $* *$ & 0.16 & $* *$ & 0.52 & \\
\hline $\mathrm{P}$ Vs H & 1 & 49.23 & & 239.78 & $* *$ & 1.63 & & 280.90 & $* *$ & 38.39 & $* *$ & 59.58 & $* *$ & 1262.25 & $* *$ & 8.93 & $* *$ & 0.02 & & 1.98 & $* *$ \\
\hline $\begin{array}{l}\text { Analar } \\
\text { Lines (L) }\end{array}$ & 2 & 1978.09 & $* *$ & 56.32 & $* *$ & 18.22 & $* *$ & 66.60 & $* *$ & 430.85 & & 426.87 & & 140.52 & $* *$ & 37.37 & & 0.33 & $* *$ & 1.72 & $* *$ \\
\hline $\begin{array}{l}\text { Babalar } \\
\text { Testers (T) }\end{array}$ & 4 & 819.15 & $* *$ & 10.06 & $* *$ & 1.23 & & 9.61 & $* *$ & 227.07 & & 243.73 & & 16.02 & & 34.75 & & 0.27 & $* *$ & 0.39 & \\
\hline$L \times T$ & 8 & 308.82 & $* *$ & 4.36 & $* *$ & 7.38 & $* *$ & 3.68 & & 254.64 & $* *$ & 241.53 & $* *$ & 11.77 & $* *$ & 41.58 & $* *$ & 0.07 & $* *$ & 0.28 & \\
\hline $\begin{array}{l}\text { Hata } \\
\text { Error }\end{array}$ & 66 & 70.26 & & 1.96 & & 1.41 & & 2.60 & & 5.51 & & 2.38 & & 5.51 & & 0.30 & & 0.0 & & 0.48 & \\
\hline
\end{tabular}

lif verimi: Lv, ekim-ilk tarak açma süresi: Ets, taraklanma periyodu: Tp, ekim-ilk çiçek açma süresi: Eiças, çiçeklenme süresi (periyodu): Çp, ekim-ilk koza açma süresi : Eikas, koza olgunlaşma süresi (ilk çiçek-III.el hasat): Kp, ortalama olgunluk süresi: Oos, günlük verim indeksi: Gvi, ilk meyve dalı boğum sayısı: Imdns

fiber yield: Lv, number of days to first squaring time from sowing: Ets, squaring period: Tp, number of days to first flowering time from sowing: Eiças, flowering period: Çp, number of days to first boll opening time from sowing: Eikas, boll maturation period: Kp, avarage of maturity time: Oos, daily yield index: Gvi, node number of first fruiting branch; imdns

*: $P<0.05, * *: P<0.01$, P:Probability 
Ekim-Ilk Çiçek Açma Süresi

Verim ile doğrudan ilişkili olmayan ekimilk çiçek açma süresi (Baloch ve ark., 2014), pamuğun olgunluk indeksini desteklemektedir (Baloch ve Veesar, 2007). Baloch ve ark., (2014), Sadori isimli çeşidin 47.35 günde, Memon ve ark., (2017) ise Sindh-1 isimli çeşidin 40 günde çiçeklenmeye başladığını bildirirken, bu çalışmaya ait ekim-ilk çiçek açma süresi, melezlerde; 72.3 gün (1x4) ile 79.3 gün $(3 \times 5)$ arasında değişerek ortalama 75.6 gün, ebeveynlerde ise 75.5 gün (Beli İzvor 432) ile 83.8 gün (Furkan) arasında değişerek ortalama 79.2 gün olmuştur. Analar arası ve babalar arası farklılıklar bu varyasyona katkı verirken, önemli GUY sahip olan Furkan ve Primera ebeveynlerine karşılık önemsiz ÖUY'ne sahip olan melezlerin ebeveynlerden $\sim 4$ gün daha erkenci (Çizelge 1 ve 2) olduğu belirlenmiştir. Bulgular, Shakeel ve ark., (2012)'nın aksine, özelliğin eklemeli gen etkisiyle $\left(\sigma^{2}{ }_{G U Y} / \sigma^{2}\right.$ öUY $\left.>1\right)$ yönetildiğine (Çizelge 3 ) ve çiçeklenme süresinin yanı sıra günlük verim indeksi ile negatif, ortalama olgunluk süresi ve ilk meyve dalı boğum sayısı ile pozitif korelasyon gösterdiğine işaret etmiştir (Çizelge 5).

\section{Çiçeklenme Süresi}

Eklemeli olmayan gen etkisiyle yönetilen $\left(\sigma_{\text {GUY }}^{2} / \sigma^{2}{ }_{\text {ÖUY }}<1\right) \quad$ çiçeklenme süresi, melezlerde; 45.5 gün (1x4) ile 80.8 gün (2x6) arasında değişerek ortalama 73.7 gün, ebeveynlerde ise; 70.3 gün (Furkan) ile 79.0 gün (Beli İzvor 432) arasında değişerek ortalama 72.3 gün olmuştur (Çizelge 2). Özellik yönünden, analar $\mathrm{x}$ babalar (LXT) interaksiyonu melezler arası, ebeveynler arası ve genotipler arası varyasyonlara \% 53.5 oranında katkı verirken, ebeveynler ortalamasının melezler ortalamasından daha küçük olduğu saptanmıştır (Çizelge 1 ve 2). Ayrıca, $1 \times 5,1 \times 6,1 \times 7,1 \times 8,2 \times 4$ ve $3 \times 4 \quad F_{1}$ melez kombinasyonları ile Adana 98, Primera ve Berke ebeveynlerine ait ÖUY ve GUY'nin önemli olduğu Çizelge 3’ten izlenirken, özelliğin ekim-ilk koza açma süresi ve ortalama olgunluk süresi hariç koza olgunlaşma süresi ve günlük verim indeksi ile negatif ve önemli korelasyon gösterdiği belirlenmiştir (Çizelge 5).

\section{Ekim-ilk Koza Açma Süresi}

Analar x babalar (LxT) ilişkisinin \% 51.38 oranında destek verdiği ve melezlerde; 121.0 gün $(1 \times 4)$ ile 155.3 gün $(2 \times 6)$ arasında değişerek ortalama 149.47 gün, ebeveynlerde ise; 147.5 gün (Fantom) ile 157.3 gün (Adana 98) arasında değişerek ortalama 151.16 gün olan ekim-ilk çiçek açma süresinin, dominant ve/veya epistatik gen etkisiyle yönetildiği ve melezler ortalamasının ebeveynler ortalamasından daha küçük olduğu saptanmıştır (Çizelge 1 ve 2). Ayrıca, 1x5, $1 \times 6,1 \times 7,1 \times 8,2 \times 4$ ve $3 \times 4 \quad F_{1}$ kombinasyonları ile Adana 98, Furkan, Primera, Berke ve Nazilli 663 ebeveynlerinin uyum yetenekleri (ÖUY ve GUY) önemli bulunurken (Çizelge 3), özelliğin koza olgunlaşma süresi ve günlük verim indeksi ile negatif ortalama olgunluk süresi ve ilk meyve dalı boğum sayısı ile de pozitif ilişki gösterdiği saptanmıştır (Çizelge 3 ve 5). 
Çizelge 2. Elbistan koşullarında, incelenen özellikler yönünden ebeveynler ve melezlere ait değerler Table 2. Values of parents and hybrids in investigated properties in Elbistan conditions

\begin{tabular}{|c|c|c|c|c|c|c|c|c|c|c|c|c|c|c|c|c|c|c|c|c|}
\hline \multirow{2}{*}{$\begin{array}{c}\text { Melezler } \\
\text { Hybrids }\end{array}$} & \multicolumn{2}{|c|}{$\begin{array}{c}\text { LV } \\
\mathrm{kg} \mathrm{da} a^{-1}\end{array}$} & \multicolumn{2}{|c|}{$\begin{array}{l}\text { Ets } \\
\text { gün } \\
\text { day }\end{array}$} & \multicolumn{2}{|c|}{$\begin{array}{l}\text { Tp } \\
\text { gün } \\
\text { day }\end{array}$} & \multicolumn{2}{|c|}{$\begin{array}{l}\text { Eiças } \\
\text { gün } \\
\text { day }\end{array}$} & \multicolumn{2}{|c|}{$\begin{array}{l}\text { Çp } \\
\text { gün } \\
\text { day }\end{array}$} & \multicolumn{2}{|c|}{$\begin{array}{l}\text { Eikas } \\
\text { gün } \\
\text { day }\end{array}$} & \multicolumn{2}{|c|}{$\begin{array}{l}\mathrm{Kp} \\
\text { gün } \\
\text { day }\end{array}$} & \multicolumn{2}{|c|}{$\begin{array}{l}\text { Oos } \\
\text { gün } \\
\text { day }\end{array}$} & \multicolumn{2}{|c|}{$\begin{array}{c}\text { Gvi } \\
\text { g }\end{array}$} & \multicolumn{2}{|c|}{$\begin{array}{l}\text { İmdns } \\
\text { Adet } \\
\text { number }\end{array}$} \\
\hline & 113.3 & $\mathrm{a}$ & 53.5 & $g-k$ & 18.8 & $\mathrm{~g}$ & 72.3 & $\mathrm{~h}$ & 45.5 & j & 121.0 & $T$ & 98.0 & ij & 169.0 & d & 1.74 & $\bar{a}$ & 5.0 & \\
\hline $1 \times 5$ & 80.7 & de & 54.3 & $f-1$ & 21.8 & $c-f$ & 76.0 & efg & 74.0 & efg & 150.0 & efg & 103.0 & def & 180.9 & bc & 1.21 & def & 4.5 & \\
\hline $1 \times 6$ & 78.8 & de & 54.3 & $f-1$ & 21.8 & $c-f$ & 76.0 & efg & 75.5 & b-e & 151.5 & de & 101.5 & $f-1$ & 180.7 & c & 1.29 & cde & 5.0 & $\mathrm{bc}$ \\
\hline $1 \times 7$ & 66.2 & $f-j$ & 52.3 & I-m & 22.3 & b-e & 74.5 & gh & 76.5 & b-e & 151.0 & def & 100.5 & $f-1$ & 181.8 & a & 0.98 & $g-k$ & 5.0 & bc \\
\hline $1 \times 8$ & 77.2 & def & 51.5 & $\mathrm{klm}$ & 21.5 & def & 73.0 & $\mathrm{~h}$ & 75.0 & $c-f$ & 148.0 & gh & 102.0 & fgh & 180.9 & bc & 1.15 & efg & 4.8 & \\
\hline $2 \times 4$ & 78.6 & de & 50.3 & $\mathrm{~m}$ & 24.3 & a & 74.5 & gh & 78.5 & $a b c$ & 153.0 & bcd & 98.5 & hij & 181.1 & $a b c$ & 1.30 & cde & 4.8 & \\
\hline $2 \times 5$ & 74.4 & $e-h$ & 53.0 & h-I & 21.5 & def & 74.5 & gh & 78.0 & $a-d$ & 152.5 & $c d$ & 99.0 & $g-j$ & 180.9 & bc & 1.10 & fgh & 4.8 & \\
\hline $2 \times 6$ & 70.7 & $e-1$ & 51.0 & Im & 23.5 & $a b$ & 74.5 & gh & 80.8 & a & 155.3 & $a b$ & 96.3 & j & 180.8 & bc & 1.19 & def & 5.0 & $\mathrm{bc}$ \\
\hline $2 \times 7$ & 73.7 & $e-h$ & 52.3 & $\mathrm{I}-\mathrm{m}$ & 23.3 & $a b c$ & 75.5 & $\mathrm{fg}$ & 77.5 & a-e & 153.0 & bcd & 99.5 & $f-1 j$ & 180.8 & c & 1.21 & def & 5.3 & $\mathrm{bc}$ \\
\hline $2 \times 8$ & 80.4 & de & 51.8 & $j-m$ & 22.5 & b-e & 74.3 & gh & 78.0 & $a-d$ & 152.3 & cde & 99.0 & ghij & 181.3 & $a b c$ & 1.18 & def & 5.0 & $\mathrm{bc}$ \\
\hline $3 \times 4$ & 72.7 & e-h & 54.5 & e-h & 22.8 & $a-d$ & 77.3 & def & 74.3 & efg & 151.5 & de & 102.8 & def & 181.6 & $\mathrm{ab}$ & 1.21 & def & 5.3 & bc \\
\hline $3 \times 5$ & 63.2 & hij & 55.8 & $c-f$ & 23.5 & $a b$ & 79.3 & bcd & 75.3 & $c-f$ & 154.5 & $b c$ & 101.8 & e-h & 181.8 & $a b c$ & 0.99 & $g-j$ & 5.5 & $a b c$ \\
\hline $3 \times 6$ & 63.4 & hij & 57.0 & bcd & 21.0 & ef & 78.0 & cde & 74.8 & def & 152.8 & $c d$ & 102.3 & efg & 180.7 & c & 1.05 & $f-1$ & 6.0 & $\mathrm{ab}$ \\
\hline $3 \times 7$ & 59.1 & ljk & 54.5 & e-h & 22.8 & $a-d$ & 77.3 & def & 70.3 & hı & 147.5 & $\mathrm{~h}$ & 106.8 & bc & 181.0 & bc & 0.92 & ijk & 5.3 & $\mathrm{bc}$ \\
\hline $3 \times 8$ & 59.2 & ijk & 53.3 & $g-k$ & 23.3 & $a b c$ & 76.5 & efg & 71.8 & fgh & 148.3 & $\mathrm{gh}$ & 105.3 & cde & 181.1 & $a b c$ & 0.93 & $h-k$ & 5.0 & $b c$ \\
\hline $\begin{array}{l}\text { Melezler ortalaması } \\
\text { Avarage of hybrids }\end{array}$ & 74.1 & & & & 22. & & 75.6 & & 73. & & 149. & & 101. & & 180.3 & & 1.1 & & 5.1 & \\
\hline
\end{tabular}


Çizelge 2. Elbistan koşullarında, incelenen özellikler yönünden ebeveynler ve melezlere ait değerler (devam)

Table 2. Values of parents and hybrids in investigated properties in Elbistan conditions (continued)

\begin{tabular}{|c|c|c|c|c|c|c|c|c|c|c|c|c|}
\hline \multicolumn{2}{|c|}{$\begin{array}{c}\text { Ebeveynler } \\
\text { Parents }\end{array}$} & $\begin{array}{c}\text { Lv } \\
\mathrm{kg} \mathrm{da}^{-1}\end{array}$ & \multicolumn{2}{|c|}{$\begin{array}{l}\text { Ets } \\
\text { gün } \\
\text { day }\end{array}$} & $\begin{array}{c}\text { Tp } \\
\text { gün } \\
\text { day }\end{array}$ & $\begin{array}{l}\text { Eiças } \\
\text { gün } \\
\text { day }\end{array}$ & $\begin{array}{l}\text { Çp } \\
\text { gün } \\
\text { day }\end{array}$ & $\begin{array}{l}\text { Eikas } \\
\text { gün } \\
\text { day }\end{array}$ & $\begin{array}{c}\text { Kp } \\
\text { gün } \\
\text { day }\end{array}$ & $\begin{array}{l}\text { Oos } \\
\text { gün } \\
\text { day }\end{array}$ & $\begin{array}{c}\text { Gvi } \\
\text { g }\end{array}$ & $\begin{array}{c}\text { İmdns } \\
\text { Adet } \\
\text { number }\end{array}$ \\
\hline Stoneville 468 & (1) & $54.6^{\mathrm{jk}}$ & 56.8 & bcd & $23.0^{\mathrm{a}-\mathrm{d}}$ & $79.8^{\text {bc }}$ & $74.8^{\text {def }}$ & $154.5^{b c}$ & $102.3^{\text {efg }}$ & $181.1^{a b c}$ & $0.88^{1 \mathrm{jk}}$ & $5.3^{b c}$ \\
\hline Adana 98 & (2) & $50.3^{k}$ & 58.0 & b & $23.3^{a b c}$ & $81.3^{b}$ & 76.0 b-e & $157.3^{a}$ & $101.0^{f-1}$ & 181.1 bc & $0.81^{k}$ & $6.5^{\mathrm{a}}$ \\
\hline Furkan & (3) & $50.0^{k}$ & 61.0 & a & $22.8^{a-d}$ & $83.8^{a}$ & $70.3^{h ı}$ & $154.0^{b c}$ & $106.8^{b c}$ & $181.3^{a b c}$ & $0.87^{j k}$ & 6.5 \\
\hline Beli İzvor 432 & (4) & 93.9 bc & 55.3 & $d-g$ & $20.3^{\mathrm{fg}}$ & $75.5^{\mathrm{fg}}$ & $79.0^{a b}$ & 151.3 def & $131.5^{a}$ & $180.8^{b c}$ & $1.35^{\mathrm{cd}}$ & 5.3 \\
\hline Primera & (5) & $76.3^{d-g}$ & 57.8 & $\mathrm{bc}$ & $23.0^{a-d}$ & $80.8^{b}$ & $67.0^{\prime}$ & $147.8^{\mathrm{gh}}$ & $110.0^{b}$ & 181.0 bc & 1.18 def & 5.0 \\
\hline Berke & (6) & $87.6^{c d}$ & 56.5 & b-e & $23.3^{a b c}$ & $79.8^{b c}$ & $69.3^{h ı}$ & $149.0^{\mathrm{fgh}}$ & 107.8 bc & $180.7^{c}$ & $1.41^{b c}$ & $4.8^{c}$ \\
\hline Nazilli 663 & (7) & $65.0^{g-j}$ & 54.3 & $f-1$ & $23.0^{a-d}$ & 77.3 def & $70.8^{\mathrm{gh}}$ & $148.0^{\mathrm{gh}}$ & $106.3^{c d}$ & $180.6^{c}$ & $0.97^{g-k}$ & $5.0^{b c}$ \\
\hline Fantom & (8) & $102.8^{\mathrm{ab}}$ & 53.8 & $f-j$ & $22.0^{\text {b-e }}$ & 75.8 efg & $71.8^{\mathrm{fgh}}$ & $147.5^{h}$ & 105.3 cde & $180.7^{c}$ & $1.56^{b}$ & $4.8^{c}$ \\
\hline $\begin{array}{l}\text { Ebeveynler ort } \\
\text { Avarage of par }\end{array}$ & & 72.6 & 56 & & 22.5 & 79.2 & 72.4 & 151.2 & 108.8 & 180.9 & 1.30 & 5.4 \\
\hline $\begin{array}{l}\text { Genel ortalama } \\
\text { Avarage of gen }\end{array}$ & & 73.6 & 54 & & 22.4 & 76.8 & 73.2 & 150.1 & 103.8 & 180.5 & 1.13 & 5.2 \\
\hline CV (\%) & & 11.39 & 2. & & 5.30 & 2.10 & 3.21 & 1.03 & 2.26 & 0,30 & 1.15 & 13.43 \\
\hline $\begin{array}{l}\text { LSD Genotipler } \\
\text { LSD }_{\text {Genotypies }}\end{array}$ & & 11.80 & 0. & & 1.65 & 3.98 & 3.74 & 2.49 & 3.74 & 0.77 & 10.86 & 1.02 \\
\hline
\end{tabular}


Çizelge 3. Genotiplerin lif verimi ve erkencilik özelliklerine ilişkin ÖUY ile GUY değerleri ve önemlilikleri Table 3. GCA and SCA values of parents and hybrids for investigated fiber yield and earliness properties

\begin{tabular}{|c|c|c|c|c|c|c|c|c|c|c|c|c|c|c|}
\hline $\begin{array}{c}\text { Melezler } \\
\text { Hybrids }\end{array}$ & $\begin{array}{c}\text { Lv } \\
\text { kg da }{ }^{-1}\end{array}$ & $\begin{array}{l}\text { Ets } \\
\text { gün } \\
\text { day }\end{array}$ & $\begin{array}{c}\mathrm{Tp} \\
\text { gün } \\
\text { day }\end{array}$ & & $\begin{array}{l}\text { Eiças } \\
\text { gün } \\
\text { day }\end{array}$ & $\begin{array}{l}\text { Çp } \\
\text { gün } \\
\text { day }\end{array}$ & & $\begin{array}{c}\text { Eikas } \\
\text { gün } \\
\text { day }\end{array}$ & & $\begin{array}{l}\text { Kp } \\
\text { gün } \\
\text { day }\end{array}$ & $\begin{array}{l}\text { Oos } \\
\text { gün } \\
\text { day }\end{array}$ & & Gvi & $\begin{array}{l}\text { İmdns } \\
\text { Adet } \\
\text { number }\end{array}$ \\
\hline $1 \times 4$ & $15.96 * *$ & 0.87 & -2.08 & & -1.22 & -16.18 & & -15.67 & & -1.68 & -6.63 & & $0.21 * *$ & 0.22 \\
\hline $1 \times 5$ & -1.17 & 0.03 & 0.58 & & 0.62 & 2.65 & $*$ & 2.83 & $* *$ & 1.82 & 1.49 & $* *$ & 0.00 & -0.20 \\
\hline $1 \times 6$ & -1.32 & 0.28 & 0.75 & & 1.03 & 2.90 & $*$ & 3.50 & $* *$ & 1.57 & 1.58 & $* *$ & 0.00 & -0.12 \\
\hline $1 \times 7$ & -9.28 & -0.63 & 0.58 & & -0.05 & 6.15 & $* *$ & 5.67 & $* *$ & -1.68 & 2.20 & $* *$ & -0.17 & 0.05 \\
\hline $1 \times 8$ & -4.19 & -0.55 & 0.17 & & -0.38 & 4.48 & $* *$ & 3.67 & $* *$ & -0.02 & 1.37 & $* *$ & -0.04 & 0.05 \\
\hline $2 \times 4$ & -11.05 & -0.88 & 1.62 & $* *$ & 0.73 & 7.57 & $* *$ & 7.43 & $* *$ & 1.37 & 3.17 & $* *$ & -0.15 & -0.13 \\
\hline $2 \times 5$ & 0.15 & 0.28 & -1.47 & & -1.18 & -2.60 & & -3.57 & & 0.37 & -0.79 & & -0.03 & -0.05 \\
\hline $2 \times 6$ & -1.71 & -1.47 & 0.70 & & -0.77 & -1.10 & & -1.65 & & -1.13 & -0.67 & & -0.02 & -0.22 \\
\hline $2 \times 7$ & 5.95 & 0.87 & -0.22 & & 0.65 & -2.10 & & -1.23 & & -0.13 & -1.16 & & $0.14 *$ & 0.20 \\
\hline $2 \times 8$ & 6.66 & 1.20 & -0.63 & & 0.57 & -1.77 & & -0.98 & & -0.47 & -0.55 & & 0.06 & 0.20 \\
\hline $3 \times 4$ & -4.91 & 0.02 & 0.47 & & 0.48 & 8.62 & $* *$ & 8.23 & $* *$ & 0.32 & 3.46 & $* *$ & -0.06 & -0.08 \\
\hline $3 \times 5$ & 1.02 & -0.32 & 0.88 & & 0.57 & -0.05 & & 0.73 & & -2.18 & -0.70 & & 0.04 & 0.25 \\
\hline $3 \times 6$ & 3.03 & 1.18 & -1.45 & & -0.27 & -1.80 & & -1.85 & & -0.43 & -0.91 & & 0.02 & 0.33 \\
\hline $3 \times 7$ & 3.33 & -0.23 & -0.37 & & -0.60 & -4.05 & & -4.43 & & 1.82 & -1.03 & & 0.03 & -0.25 \\
\hline $3 \times 8$ & -2.47 & -0.65 & 0.47 & & -0.18 & -2.72 & & -2.68 & & 0.48 & -0.82 & & -0.02 & -0.25 \\
\hline
\end{tabular}


Çizelge 3. Genotiplerin lif verimi ve erkencilik özelliklerine ilişkin ÖUY ile GUY değerleri ve önemlilikleri (devam)

Table 3. GCA and SCA values of parents and hybrids for investigated fiber yield and earliness properties (continued)

\begin{tabular}{|c|c|c|c|c|c|c|c|c|c|c|c|c|c|c|c|}
\hline \multicolumn{2}{|c|}{$\begin{array}{c}\text { Ebeveynler } \\
\text { Parents }\end{array}$} & $\begin{array}{c}\text { Lv } \\
\mathrm{kg} \mathrm{da}^{-1}\end{array}$ & $\begin{array}{l}\text { Ets } \\
\text { gün } \\
\text { day }\end{array}$ & & $\begin{array}{l}\mathrm{Tp} \\
\text { gün } \\
\text { day }\end{array}$ & $\begin{array}{l}\text { Eiças } \\
\text { gün } \\
\text { day }\end{array}$ & $\begin{array}{l}\text { Çp } \\
\text { gün } \\
\text { day }\end{array}$ & & $\begin{array}{l}\text { Eikas } \\
\text { gün } \\
\text { day }\end{array}$ & & $\begin{array}{l}\mathrm{Kp} \\
\text { gün } \\
\text { day }\end{array}$ & $\begin{array}{l}\text { Oos } \\
\text { gün } \\
\text { day }\end{array}$ & & Gvi & $\begin{array}{l}\text { İmdns } \\
\text { Adet } \\
\text { number }\end{array}$ \\
\hline Stoneville 468 & (1) & $9.13^{* *}$ & $\begin{array}{l}-0.12 \\
\end{array}$ & & $\begin{array}{l}-1.08 \\
\end{array}$ & -1.20 & -4.40 & & -5.17 & & -0.07 & $\begin{array}{l}-1.58 \\
\end{array}$ & & $0.11^{* *}$ & $\begin{array}{l}-0.22 \\
\end{array}$ \\
\hline Adana 98 & (2) & 1.46 & -1.62 & & $0.72 * *$ & -0.90 & 4.85 & $* *$ & 3.73 & $* *$ & -2.62 & 0.72 & ** & 0.03 & -0.12 \\
\hline Furkan & (3) & -10.60 & 1.73 & $* *$ & 0.37 & $2.10^{* *}$ & -0.45 & & 1.43 & $* *$ & $2.68^{* *}$ & 0.86 & ** & -0.14 & $0.33 *$ \\
\hline Beli İzvor 432 & (4) & $14.06^{* *}$ & -0.52 & & -0.37 & -0.88 & -7.62 & & -7.63 & & -1.32 & -3.03 & & $0.25 * *$ & -0.07 \\
\hline Primera & (5) & -1.33 & 1.07 & $*$ & -0.03 & $1.03 *$ & 2.05 & $* *$ & 2.87 & $* *$ & 0.18 & 0.75 & ** & -0.06 & -0.15 \\
\hline Berke & (6) & -3.10 & 0.82 & $*$ & -0.20 & 0.62 & 3.30 & $* *$ & 3.70 & $* *$ & -1.07 & 0.48 & $* *$ & 0.02 & 0.27 \\
\hline Nazilli 663 & (7) & -7.78 & -0.27 & & 0.47 & 0.20 & 1.05 & & 1.03 & $*$ & 1.18 & 0.96 & $* *$ & -0.13 & 0.10 \\
\hline Fantom & (8) & -1.85 & -1.10 & & 0.13 & -0.97 & 1.22 & & 0.03 & & 1.02 & 0.84 & $* *$ & -0.08 & -0.15 \\
\hline $\begin{array}{l}\sigma_{G U Y}^{2} \\
\sigma_{G C A}^{2}\end{array}$ & & 17.04 & 0.38 & & 0.03 & 0.45 & 2.13 & & 2.45 & & 0.85 & 0.13 & & 0.004 & 0.01 \\
\hline $\begin{array}{l}\sigma_{\text {ÖUY }}^{2} \\
\sigma_{\text {SCA }}^{2}\end{array}$ & & 59.64 & 0.60 & & 1.49 & 0.27 & 62.28 & & 59.79 & & 1.56 & 10.32 & & 0.01 & -0.05 \\
\hline $\begin{array}{l}\sigma_{G U Y}^{2} / \sigma^{2}{ }_{\text {OUY }} \\
\sigma_{G C A}^{2} \sigma_{S C A}^{2}\end{array}$ & & 0.29 & 0.64 & & 0.02 & 1.65 & 0.03 & & 0.04 & & 0.54 & 0.01 & & 0.34 & -0.22 \\
\hline
\end{tabular}




\section{Koza Olgunlaşma Süresi}

Özellik yönünden önemli bulunan melezler arası, ebeveynler arası ve genotipler arası farklılıklara analar arası farklılıklar ile analar $x$ babalar (LXT) interaksiyonu destek verirken, melezler ortalaması ebeveynler ortalamasından daha az bulunmuştur (Çizelge 1 ve 2). Dominant ve/veya epistatik gen etkisiyle yönetilen (Çizelge 3) koza olgunlaşma süresi, melezlerde 98.0 gün (1x4) ile 106.8 gün (3x7) arasında değişerek ortalama 101.1 gün, ebeveynlerde ise 101.0 gün (Adana 98) ile 131.5 gün (Beli İzvor 432) arasında değişerek ortalama 108.8 gün olmuş ve melezler arası varyasyona en yüksek katkıyı \% 63.98 ile analar sağlamıştır. Çalışmada, melezlere ait ÖUY ile Furkan çeşidi hariç, diğer ebeveynlerin GUY önemsiz bulunurken, özelliğin ortalama olgunluk süresi ve ilk meyve dalı boğum sayısı ile negatif korelasyon gösterdiği saptanmıştır (Çizelge 5).

Çizelge 4.Elbistan koşullarında analar, babalarve analar $\mathrm{x}$ babalar ilişkisinin lif verimi ve erkencilik özelliklerine katkı düzeyi

Table 4. Effect values of lines, testers and line $x$ tester interaction on yield and earliness properties in Elbistan conditions.

\begin{tabular}{|c|c|c|c|}
\hline $\begin{array}{l}\text { Özellikler } \\
\text { Properties }\end{array}$ & $\begin{array}{l}\text { Analar } \\
\text { Lines } \\
(\%)\end{array}$ & $\begin{array}{c}\text { Babalar } \\
\text { Testers } \\
(\%)\end{array}$ & $\begin{array}{c}\text { Analar x Babalar } \\
\text { Lines } \times \text { Testers } \\
(\%)\end{array}$ \\
\hline $\begin{array}{l}\text { Lif verimi }\left(\mathrm{kg} \mathrm{da}^{-1}\right) \\
\text { Lint yield }\left(\mathrm{kg} \mathrm{da}^{-1}\right)\end{array}$ & 40.77 & 33.77 & 25.46 \\
\hline $\begin{array}{l}\text { Ekim-ilk tarak süresi (gün) } \\
\text { Sowing-first squaring time (day) }\end{array}$ & 60.00 & 21.43 & 18.57 \\
\hline $\begin{array}{l}\text { Taraklanma süresi (gün) } \\
\text { Squaring period (day) }\end{array}$ & 36.28 & 4.91 & 58.81 \\
\hline $\begin{array}{l}\text { Ekim-ilk çiçek süresi (gün) } \\
\text { Sowing-first flowering time (day) }\end{array}$ & 66.24 & 19.11 & 14.65 \\
\hline $\begin{array}{l}\text { Çiçeklenme süresi (gün) } \\
\text { Flowering period (day) }\end{array}$ & 22.63 & 23.86 & 53.51 \\
\hline $\begin{array}{l}\text { Ekim-ilk koza açma süresi (gün) } \\
\text { Sowing-first boll opening time (day) }\end{array}$ & 22.70 & 25.92 & 51.38 \\
\hline $\begin{array}{l}\text { Koza olgunlaşma süresi (ilk çiçek-IIl.el hasat) (gün) } \\
\text { Boll maturity period (day) }\end{array}$ & 63.98 & 14.59 & 21.43 \\
\hline $\begin{array}{l}\text { Ortalama olgunluk süresi (gün) } \\
\text { Avarage maturity period (day) }\end{array}$ & 13.68 & 25.44 & 60.88 \\
\hline $\begin{array}{l}\text { Günlük verim indeksi (\%) } \\
\text { Daily yield index (\%) }\end{array}$ & 29.22 & 47.86 & 22.93 \\
\hline $\begin{array}{l}\text { Illk meyve dalı boğum sayısı (adet) } \\
\text { Node number of first sympodial brannches (number) }\end{array}$ & 47.47 & 21.66 & 30.88 \\
\hline $\begin{array}{l}\text { Ortalama } \\
\text { Mean }\end{array}$ & 40.30 & 23.86 & 35.85 \\
\hline
\end{tabular}

Ortalama Olgunluk Süresi

Analar x babalar (LXT) ilişkisinin \% 60.88 düzeyinde destek verdiği ortalama olgunluk süresi, melezlerde; 169.0 gün (1x4) ile 181.8 gün (1x7 ve $3 \times 5)$ arasında değişerek ortalama 180.3 gün, ebeveynlerde ise; 180.6 gün (Nazilli 663) ile 181.3 gün (Furkan) arasında değişerek 
ortalama 180.9 gün olmuştur. Dominant ve/veya epistatik genler ile yönetilen özellik yönünden (Çizelge 3 ), 1x5, 1x6, $1 \times 7,1 \times 8,2 \times 4$ ve $3 \times 4 F_{1}$ kombinasyonları ile Adana 98, Furkan, Primera Berke, Nazilli 663 ve Fantom ebeveynlerine ait uyuşma yetenekleri (ÖUY ve GUY) önemli bulunmuş ve özelliğin taraklanma süresi, ekimi-ilk çiçek açma süresi, çiçeklenme periyodunun yanı sıra ekim-ilk koza açma süresiyle pozitif, koza süresi ile de negatif korelasyon gösterdiği saptanmıştır.

Çizelge 5. Elbistan koşullarında incelenen lif verimi ile erkencilik özellikleri arasındaki korelasyon katsayıları

Table 5. Correlation coefficients among investigated properties in Elbistan conditions

\begin{tabular}{ccccccccccc}
\hline $\begin{array}{c}\text { Özellikler } \\
\text { Properties }\end{array}$ & 1 & 2 & 3 & 4 & 5 & 6 & 7 & 8 & 9 & 10 \\
\hline 1 & & $*$ & $* *$ & $* *$ & $* *$ & $* *$ & $* *$ & $* *$ & $* *$ & $* *$ \\
2 & -0.26 & & & $* *$ & $* *$ & & $*$ & & $*$ & \\
3 & -0.45 & -0.10 & & $* *$ & $* *$ & $* *$ & $* *$ & $* *$ & $* *$ & \\
4 & -0.47 & 0.87 & 0.40 & & $* *$ & & & $* *$ & & $* *$ \\
5 & -0.39 & -0.26 & 0.31 & -0.08 & & $* *$ & $* *$ & $* *$ & $* *$ & \\
6 & -0.57 & 0.15 & 0.47 & 0.37 & 0.89 & & $* *$ & $* *$ & $* *$ & $*$ \\
7 & 0.39 & 0.26 & -0.31 & 0.08 & -1.00 & -0.89 & & $* *$ & $* *$ & $*$ \\
8 & -0.51 & 0.09 & 0.48 & 0.32 & 0.77 & 0.86 & -0.77 & & $* *$ & $* *$ \\
9 & 0.97 & -0.21 & -0.43 & -0.40 & -0.37 & -0.52 & 0.37 & -0.51 & & \\
10 & -0.35 & 0.37 & 0.09 & 0.39 & 0.03 & 0.20 & -0.03 & 0.07 & -0.30
\end{tabular}

1-Lif verimi, 2- Ekim-Taraklanma süresi, 3-Taraklanma süresi, 4-Ekim-illk çiçek açma süresi, 5-Çiçeklenme süresi, 6Ekim-illk koza açma süresi, 7-Koza olgunlaşma süresi, 8-Ortalama olgunluk süresi, 9-Günlük verim indeksi, 10-illk meyve dalı boğum sayısı.

1-fiber yield, 2-sowing-first squaring time, 3-squaring period, 4-sowing-first flowering time, 5-flowering period, 6sowing-first boll opening time, 7-boll maturation period, 8-avarage of maturity time, 9-daily yield index, 10-node number of first fruiting branch.

\section{Günlük Verim Indeksi}

Eklemeli olmayan gen etkisiyle yönetilen günlük verim indeksi varyasyonuna, analar arası ve babalar arası farklııkların yanı sıra, analar $\mathrm{x}$ babalar (LXT) interaksiyonu katkı vermiştir. Günlük verim indeksi, melezlerde; \% 1.74 (1x4) ile \% 0.92 (3x7) arasında değişerek ortalama \% 1.16, ebeveynlerde ise; \% 1.56 (Fantom) ile \% 0.81 (Adana 98) arasında değişerek ortalama \% 1.30 olarak gerçekleşmiştir (Çizelge 2). Özellik yönünden, melezler ve ebeveynlere ait ortalamalar arasında fark bulunamazken (Çizelge 1 ve 2), $1 \times 4$ ve
$2 \times 7$ kombinasyonları ile Stoneville 468 ve Beli İzvor 432 ebeveynlerine ait uyum yeteneklerinin (ÖUY ve GUY) önemli olduğu (Çizelge 3 ) ve özelliğin koza olgunlaşma süresi ile pozitif, ekim-ilk tarak açma süresi, taraklanma süresi, çiçeklenme süresi, ekim-ilk koza açma süresi ve ortalama olgunluk süresi ile de negatif korelasyon gösterdiği saptanmıştır.

\section{Ilk Meyve Dalı Boğum Sayısı}

En güvenli erkencilik kriteri olan (Igbal ve ark., 2003) ilk meyve dalı boğum sayısı, hem eklemeli (Rauf ve ark., 2005) 
hem de çevresel varyansla yönetilmektedir (Ray ve Richmond, 1966). Bu çalışmada, dominant ve/veya epistatik gen etkisiyle yönetildiği belirlenen (Çizelge 3) ilk meyve dalı boğum sayısının, melezlerde; 4.5 adet $(1 \times 5)$ ile 6.0 adet $(3 \times 6)$ arasında değişerek ortalama 5.1 adet, ebeveynlerde ise; 4.8 adet (Berke ve Fantom) ile 6.5 adet (Adana 98 ve Furkan) arasında değişerek ortalama 5.4 adet olduğu ve anaların hem melezler arası hem de ebeveynler arası varyasyona \% 47.47 oranında destek verdiği belirlenmiştir. Özellik, ekim-ilk çiçek açma süresi ve ekim-ilk koza açma süresi ile pozitif, ortalama olgunluk süresiyle de negatif ve önemli korelasyon gösterirken, melezler ortalamasının, ebeveynler ortalamasından önemli oranda küçük (Çizelge 1 ve 2) ve Furkan çeşidine ait GUY'nin önemli olduğu saptanmıştır.

\section{Sonuç}

Çalışma sonucunda, en yüksek günlük verim indeksine sahip $1 \times 4 F_{1}$ (Stoneville 468 x Beli İzvor 432) melezi ile en kısa ekim-ilk taraklanma süresine sahip Fantom çeşidinin aynı zamanda en kısa ekim-ilk koza açma süresi ile en yüksek lif verimine sahip olduğu saptanmıştır. Çalışmada, 1x4 $F_{1}$ melezine ait ÖUY'nin yanı sıra, bu melezin ebevenyleri olan Stoneville 468 ile Beli İzvor 432 çeşitlerine ait GUY önemli bulunurken, 1x4 $F_{1}$ melezi lif verimi yönünden ana ebeveyn, günlük verim indeksi yönünden ise baba ebeveyn tarafından desteklenmiştir. Ayrıca, lif verimi, incelen erkencilik özelliklerinin tamamı ile önemli korelasyon göstermiştir. Bu ilişki koza periyodu ve günlük verim indeksi ile pozitif, diğer özelliklerle negatif yönlü olurken, lif verimi ile günlük verim indeksinin \% 66 oranında dominant ve/veya epistatik gen etkisiyle yönetildiği saptanmıştır. Bu veriler neticesinde ise erkenciliği lif verimi ile kombine eden $1 \times 4$ $F_{1}$ melezi (Stoneville $468 \times$ Beli İzvor 432) ile Fantom çeşidinin Elbistan koşulları için uygun genotipler olduğu tespit edilmiştir.

\section{Teşekkür}

Çalışma, TÜBiTAK (TOVAG-1100369) ve TAGEM (Doğu Akdeniz Geçit Kuşağı Tarımsal Araştırma Enstitüsü) tarafından desteklenmiş olup, bu kurumlara teşekkür ederim.

\section{Ekler}

Anonim, 2009 a. Kahramanmaraş il Gıda Tarım ve Hayvancılık Müdürlüğü, toprak laboratuar analiz sonuçları. Kahramanmaraş.

Anonim, 2009 b. Elbistan Meteoroloji ilçe Müdürlüğü, gözlem kayıtları. Kahramanmaraş.

Anonim, 2013 a. Aydın Ticaret Borsası, yıllık pamuk raporu. Aydın.

Anonim, 2013 b. www.elbistan.gov.tr ve www.elbistan.bel.tr. Erişim tarihi:12.01.2013.

Başbağ, S., 1999. Güneydoğu Anadolu Bölgesi standart pamuk çeşitlerinden Sayar 314 ile erkenci Ogosta 644 Çeşidinin $F_{1}, F_{2}$ ve geri melez döl kuşaklarında verim, kalite ve erkencilik kriterlerinin kalıtımı. Doktora Tezi, Çukurova Üniversitesi Fen Bilimleri Enstitüsü, Adana, 77s.

Bednarz, C.W., Nichols, R.L., 2005. Phenological and morphological components of cotton crop maturity. Crop Science, 45 (4): 1497- 
1503.

Bilbro, J.D., Quisenberry, JE., 1975. A yieldrelated measure earliness for cotton. Crop Science, 13 (3): 392-393.

Baloch, M.J., Veesar, N.F., 2007. Identification of plant traits for characterization of early maturing upland cotton varieties. Pakistan Journal of Scientific and Industrial Research, 50: 128-132.

Baloch, M.J., Khan, N.U., Rajput, M.A,. Jatoi, W.A., Gul, S., Rind, I.H., Veesar, N.F., 2014. Yield related morphological measures of short duration cotton genotypes. The Journal of Animal \& Plant Sciences, 24 (4): 1198-1211.

Bölek, Y., Oğlakçı, M., Kıllı, F., 2007. Pamukta (Gossypium spp.) erkenciliği belirleyen faktörler ve üretim planlaması. Kahramanmaraş Sütçü Imam Üniversitesi Fen ve Mühendislik Dergisi, 10 (1): 116125.

Christidis, B.G., Harisson, G.J., 1955. Cotton Growing Problems. Mc. Graw Hill Book Company Inc. Newyork, USA.

Gipson, J.R., Ray, L.L., 1970. Temperature variety interrelationships in cotton. 1. Boll and fibre development. Cotton Growing Review, 47 (4): 257-263.

Hesketh, J.D., Lane, H.C., Alberte, R.S., Fox, S., 1975. Earliness factor in cotton: new comparisons among genotypes. Cotton Growing Review, 52: 126-133.

Iqbal, M., Chang, M.A., Jabbar, A., Iqbal, M.Z., Hassan, M., Islam, N., 2003. Inheritance of earliness and other characters in upland cotton. Online Journal of Biological Sciences, 3 (6): 585-590.

Kassianenko, V.A., Dragavtsev, V.A., Razorenov, G.I., Razorenova, T.S., 2003. Variability of cotton (Gossypium hirsutum L.) with regard to earliness. Genetic Resources and Crop Evolution, (50): 157-163.

Low, A., Hesketh, J., Muramoto, H., 1969. Some environmental effects on the varietal node number of the first fruiting branch. Cotton Growing Review, 40: 181-188.

Memon, S., Jatoi, W.A., Khanzada, S., Kamboh, N., Rajput, L., 2017. Line $\times$ Tester Analysis for earliness yield and yield contributing traits in Gossypium hirsutum L., Journal of Basic \& Applied Sciences, (13): 287-292.

Mert, M., Akışcan, Y., 1995. Amik Ovası koşullarında bazı pamuk (Gossypium hirsutum L.) çeşitlerinin gelişme dönemlerine göre sıcaklık isteklerinin belirlenmesi. Türkiye VI. Tarla Bitkileri Kongresi, 5-9 Eylül, pp (1): 291-296, Antalya.

Muramoto, H., Hesketh, J.D., Baker, D.N., 1971. Cold tolerance in hexaploid cotton. Crop Science, 11: 589-591.

Shah, K.N., Rauf, S., Afzal, I., 2005. A genetic study of some earliness related characters in cotton (Gossypium hirsutum L.). Caderno de Pesquisa Série Biologia, Santa Cruz do Sul 17 (1): 81-93.

Ray, L.L., Richmond, T.R., 1966. Morphological measures of earliness of crop maturity in cotton. Crop Science, 6: 527-531

SAS., 2002. A business unit of sas Copyright, 1989-2002, SAS Institute Inc. http://www.jmp.com.

Shakeel, A., Farooq, J., Bibi, A., Khan, S.H., Saleem, M.F., 2012. Genetic studies of earliness in Gossypium hirsutum L. International Journal for Agro Veterinary and Medical Sciences, 6 (3): 189-207.

Singh, R.K, Chaudhary, B.D., 1985. Biometrical Methods in quantitative genetic analysis. Kalyani Publishers, New Delhi, Ludhiana, India. 39-78 p. 